\title{
Gaceta Médica de México y sus números en el año 2020
}

\section{Gaceta Médica de México and its 2020 issues}

\author{
Alejandro Treviño-Becerra y Francisco Espinosa-Larrañaga* \\ Gaceta Médica de México, Academia Nacional de Medicina de México, Ciudad de México, México
}

Debido a que en el informe anual de 2020 dirigido por el secretario general de la Academia Nacional de Medicina de México a los miembros de esta institución solo se incluye una breve información sobre Gaceta Medica de México y a que los lectores no tienen acceso a ese documento e, incluso, algunos académicos no lo conocen, consideramos prudente proporcionar las cifras siguientes.

Durante el año 2020, la revista recibió 989 trabajos, lo que significó un incremento de casi $30 \%$ respecto a 2019. Se contó con 174078 visitas a las páginas web en 83140 sesiones, 53662 usuarios nuevos y 54257 usuarios previamente registrados. Los usuarios nacionales correspondieron a 25905 y el resto a 143 países, de los cuales los primeros cinco fueron España $(n=3687)$, Estados Unidos $(n=2887)$, Colombia $(n=2871)$, Brasil $(n=2658)$ y Perú $(n=2513)$. China ocupó el séptimo lugar con 1353 usuarios, seguida de Chile, Argentina, India, Italia, Emiratos Árabes, Turquía, Japón, Canadá y Francia. El número de lectores, el cual ha crecido año con año, así como el número de académicos que publican en Gaceta, ha favorecido para que el factor de impacto se eleve en $105.3 \%$ respecto al de 2019 (0.283 a 0.581), con lo cual la revista se constituyó como la publicación mexicana que proporcionalmente más elevó esta medición.

Un problema toral que retarda la publicación es la actuación de los "revisores", quienes en ocasiones no contestan a la invitación, aceptan la invitación, pero no hacen la revisión; hacen tardíamente la revisión o emiten una opinión muy opuesta al otro revisor del artículo.
De tener una pronta aceptación y respuesta por parte de ellos tomaría de tres a cuatro meses desde la recepción correcta del manuscrito hasta su publicación.

Los números próximos están saturados en su capacidad de 120 páginas por número, por lo que la espera de publicación se podría prolongar, lo cual lleva a conjeturar sobre la necesidad y posibilidad de publicar nueve números al año, dependiendo de las finanzas, cuyo estado es crítico, lo que lleva a su vez a plantear la posibilidad de que la revista cobre por publicar y por lectura para que disponga de ingresos económicos propios.

De hecho, se está implementando la primera opción, ya que en 2019 publicamos dos suplementos adicionales a los seis números ordinarios y en 2020 , tres suplementos y un número especial con los 24 manuscritos que llegaron sobre COVID-19 en los primeros ocho meses de la pandemia. Para lograr la publicación de más número regulares sería necesario aumentar la cantidad de personal de Gaceta y establecer un plan de comercialización e, incluso, el punto de equilibrio, como en todo negocio, que podría retomar la impresión de una cantidad razonable de ejemplares.

Es momento de que los académicos se "asomen" más a Gaceta Médica de México y consideren a la revista como su primera opción de publicación; con ello esperaríamos que en meses aumente el factor de impacto a valores no sospechados.

En 2017, en el artículo editorial "Presentación del Editor de Gaceta Médica de México", publicado con
Correspondencia:

*Francisco Espinosa-Larrañaga.

E-mail: kraussg@prodigy.net.mx

0016-3813/@ 2021 Academia Nacional de Medicina de México, A.C. Publicado por Permanyer. Este es un artículo open access bajo la licencia
Fecha de recepción: 17-03-2021

Fecha de aceptación: 19-03-2021

DOI: 10.24875/GMM.M21000498
Gac Med Mex. 2021;157:1-2

Disponible en PubMed www.gacetamedicademexico.com
atículo open access bajo la licencia 
motivo del inicio de actividades del comité editorial al que estamos integrados, se indicó lo siguiente:

Gaceta Médica de México ha tenido épocas ricas en logros y ha tenido tiempos difíciles y de riesgo, pero persiste gracias a la fortaleza de la Academia Nacional de Medicina de México y al trabajo generoso de sus miembros.

Además, se señalaron algunas condiciones que se necesitan para ser editor. En las observaciones se concluyó que se requiere conocimiento, experiencia y dedicación, así como disciplina y, sobre todo, tiempo. Para 2019, se indicó que...

El transcurso de los años mostrará si habrá reducción o aumento de trabajos para publicación y de lectores, así como las repercusiones sobre el factor de impacto y otros índices bibliométricos.
Al inicio de 2021, el presidente actual de la Academia Nacional de Medicina de México, José Halabe Cherem, ratificó la dirección editorial de Gaceta. Los doctores Raúl Carrillo Esper y Fabio Gerardo Rico Méndez se incorporan como editores asociados y la oficina editorial continúa a cargo de Alma Morales. Vale la pena resaltar que la revista no recibirá ningún apoyo económico de fuentes gubernamentales.

Finalmente, queremos agradecer de manera muy especial al doctor Miguel Cruz López y a la doctora Ma. Eugenia Rodríguez Pérez, por habernos acompañado en este viaje de aventura editorial durante cuatro y tres años, respectivamente. Su dedicación, profesionalismo y objetividad han sido muy importantes para conseguir los logros aquí mencionados. 